\title{
Spatio-Temporal Information Management to Control the COVID-19 Epidemic: Country Perspectives in Europe
}

\author{
Marije Louwsma and Hartmut Müller
}

The COVID-19 pandemic puts a heavy burden on populations, health care systems and governments alike. Europe has been one of the first epicenters of the pandemic, with a huge number of reported cases and fatalities. National governments in Europe applied a range of measures to mitigate the impact of the outbreak. Infectious diseases such as COVID-19 spread from person to person and thus in space and time. Local outbreaks occur frequently and different spatial distribution patterns can be observed. Therefore, policy makers and health care services have to respond to regional dynamics of new infections on a local basis. Theis chapter illustrates the state-of-the-art of providing COVID-19 information using selected EU countries as examples. From a supranational perspective, it can be stated that the most up-to-date data at national and sub-national level can be found in national dashboards, at the most detailed NUTS 3 level or even more detailed. The integrated view and analysis of COVID-19 data from different sources reveals a wide variety of difficulties, such as timeliness of reporting, ambiguous definitions of cases and fatalities, to name a few. In Europe, the potential of an integrated system is not yet fully exploited due to the obstacles identified. It remains to be seen to what extent and when this situation will improve in the future.

\subsection{Introduction}

After having recently published a Global Influenza Strategy 2019-2020 [1], on 11 March 2020, the World Health Organization WHO 'made the assessment that COVID-19 can be characterized as a pandemic' [2]. On 13 March 2020 WHO stated that 'Europe has now become the epicenter of the pandemic, with more reported cases and deaths than the rest of the world combined, apart from China'. On 19 March 2020 UN Secretary-General stated that 'the coronavirus pandemic is a crisis unlike any in the UN's 75-years history'. Apart from the people that contracted the disease, the epidemic put a heavy burden on health care and governments the like. Early detection, laboratory testing, isolation, contact tracing and referral of patients had to be managed. Furthermore, the demands of responding directly to COVID-19 while maintaining essential health service delivery had to be balanced. 


\subsection{Spatiotemporal Spread of Infectious Diseases}

Infectious diseases spread from person to person and thus by their very nature in space and time. Depending on the characteristics of the disease, different spatial distribution patterns can be observed [3]. Since COVID-19 was not known before the start of the outbreak, little information was available about the circumstances that influence contamination and consequently the spatial distribution by infected people. The limited amount of information available from the first epicentres in China had to be used as the best assumption. From a global perspective, the influence of long-range airline traffic which shapes the spatiotemporal pattern of a global epidemic by forcing infections due to multiscale processes in the disease dynamics [4] is also of particular interest [5]. Experience with COVID-19 in China [6] suggests that in many cases the disease spreads under particular circumstances related to specific local environments. This results in spatially very heterogeneous distribution patterns in larger geographical areas.

To assess the impact of COVID-19 the British Health Foundation has compared the nationwide excess mortality rates in several European countries to the excess mortality rates in the COVID-19 hotspots of these countries $[7,8]$. The parameter excess mortality was chosen because the number of registered deaths in all countries can be considered as one of the most reliable statistics, which is for various reasons regarded more reliable than the figures related to the dissemination of the disease itself. Many countries do have a longstanding registration system for census data, contrary to the registration of COVID-19 patients and related casualties. There is no risk of misrepresentation due to different definitions used, as is the case with the number of deaths registered with COVID-19 as the cause of death (see discussion below).

Spatiotemporal heterogeneous distributions of disease cases demand for analyses with special consideration of the spatiality of the underlying phenomena. The national figures might not be representative for the local and regional situation, due to uneven spreading of the disease. A first step to analyze the geographical distribution of the disease is to visualize diagnosed cases on maps. Meanwhile, distribution maps as a medium of COVID-19 representation can be found all over the world in a mass of official publications, newspapers, on social media platforms, in dashboards etc. A list of resources can be found at the website of the Open Geospatial Consortium [9].

Data visualization of territories, mostly at country level, through mapping, dashboards and other techniques, is a valuable tool to present the characteristics of spatiotemporal phenomena. Geospatial analysis of the underlying geospatial data can do much more. Trends in outbreaks over time and space, hotspots of infection, applicable rules and regulations, and available resources for medical treatment can be identified and disseminated to a wider public. In times of a pandemic such as COVID-19 a global view is needed to take appropriate action at all governance levels; global, supranational, national, and local.

In health context, individual humans represent the basic unit of spatial analysis. However, publicly available data are regularly being aggregated to a sufficient extent to adhere to privacy standards and regulations to protect individuals in their right for privacy [10].

An integrated statistical and geospatial framework [11] can be used as an excellent basis for managing such aggregated health data. Once a harmonized framework of spatially referenced territorial units is given, health data can be aggregated to the predefined territorial units and be used for presentation and further spatiotemporal analysis. In fact, many national health authorities already take advantage from these possibilities by providing national COVID-19 data within their national framework used for managing statistical national data. The following section will start by describing the reference system NUTS (Nomenclature des Unités Territoriales Statistiques) used for managing statistical information in Europe. After that, a number of use cases presenting COVID-19 related epidemic data by using the NUTS system will be briefly discussed. 


\subsection{NUTS (Nomenclature Des Unités Territoriales Statistiques), the European Union's Spatial Reference for Statistical Data}

The Nomenclature of Territorial Units for Statistics (NUTS) provides a breakdown of the economic territory of the European Union into territorial units. It has been used in EU legislation since 1988, and it was converted to a formal Regulation of the European Parliament and the Council in 2003 [12]. While the national level of Member States is above NUTS, the NUTS classification consists of three hierarchical levels: each Member State is divided into NUTS 1 regions, then divided further into NUTS 2 regions, which in turn are subdivided into NUTS 3 regions. The NUTS regions regularly coincide with existing administrative units within the Member States, because the statistical data of the Member States are available for these units. A legislative procedure is in force to renew the classification, following changes in the Member States' administrative units. At EU level, the NUTS serves as a reference for the collection, development and harmonization of the European Union's regional statistics, for socio-economic analyses of the regions, and for the framing of EU regional policies.

The current NUTS nomenclature subdivides the territory of the European Union into 104 regions at NUTS 1 level, 281 regions at NUTS 2 level and 1,348 regions at NUTS 3 level. The NUTS Regulation defines the population size as a key indicator for comparability, laying down minimum and maximum thresholds for the population (Table 20.1).

TABLE 20.1

Population Size of the European Union's Administrative Units (Source: [12])

\begin{tabular}{c|c|c}
\hline Level & Min. number of inhabitants & Max. number of inhabitants \\
\hline NUTS 1 & 3 million & 7 million \\
NUTS 2 & 800.000 & 3 million \\
NUTS 3 & 150.000 & 800.000 \\
\hline
\end{tabular}

Following the heterogeneous population density across the EU territory this definition results in a wide span of both area size and population number: the largest NUTS 1 region is Manner-Suomi (Finland), covering $336,859 \mathrm{~km}^{2}$, the smallest region, Région de Bruxelles-Capitale (Belgium) covers $161 \mathrm{~km}^{2}$. At NUTS 2 level, Pohjois-ja ltä-Suomi (Finland) covers 227,150 km², Ciudad Autónoma de Melilla (Spain) $13 \mathrm{~km}^{2}$, at NUTS 3 level the figures are Norrbottens län (Sweden), 105,205 km² and again Ciudad Autónoma de Melilla (Spain), $13 \mathrm{~km}^{2}$.

\subsection{COVID-19 Pandemic Data Using the NUTS System}

\subsubsection{EU Level}

Eurostat, the statistical office of the European Union situated in Luxembourg, concentrates on providing relevant statistics to tackle the implications of the Covid-19 outbreak. Eurostat maintains an interactive dashboard regarding Covid-19 developments within Europe, based on the data provided by its member states (Figure 20.1).

Note: The map in Figure 20.1 is based on information provided to ECDC by the EU/EEA Member States and UK on their subnational levels of COVID-19 transmission (NUTS 2 regions) according to the categories defined by the World Health Organization. When no information has been provided by the countries on the level of COVID-19 transmission, the region is marked as 'not reported'.

The European Union is a union of sovereign states. The EU design gives the maximum respect for the sovereignty of its member states. At the same time, it ensures that the system is operational 


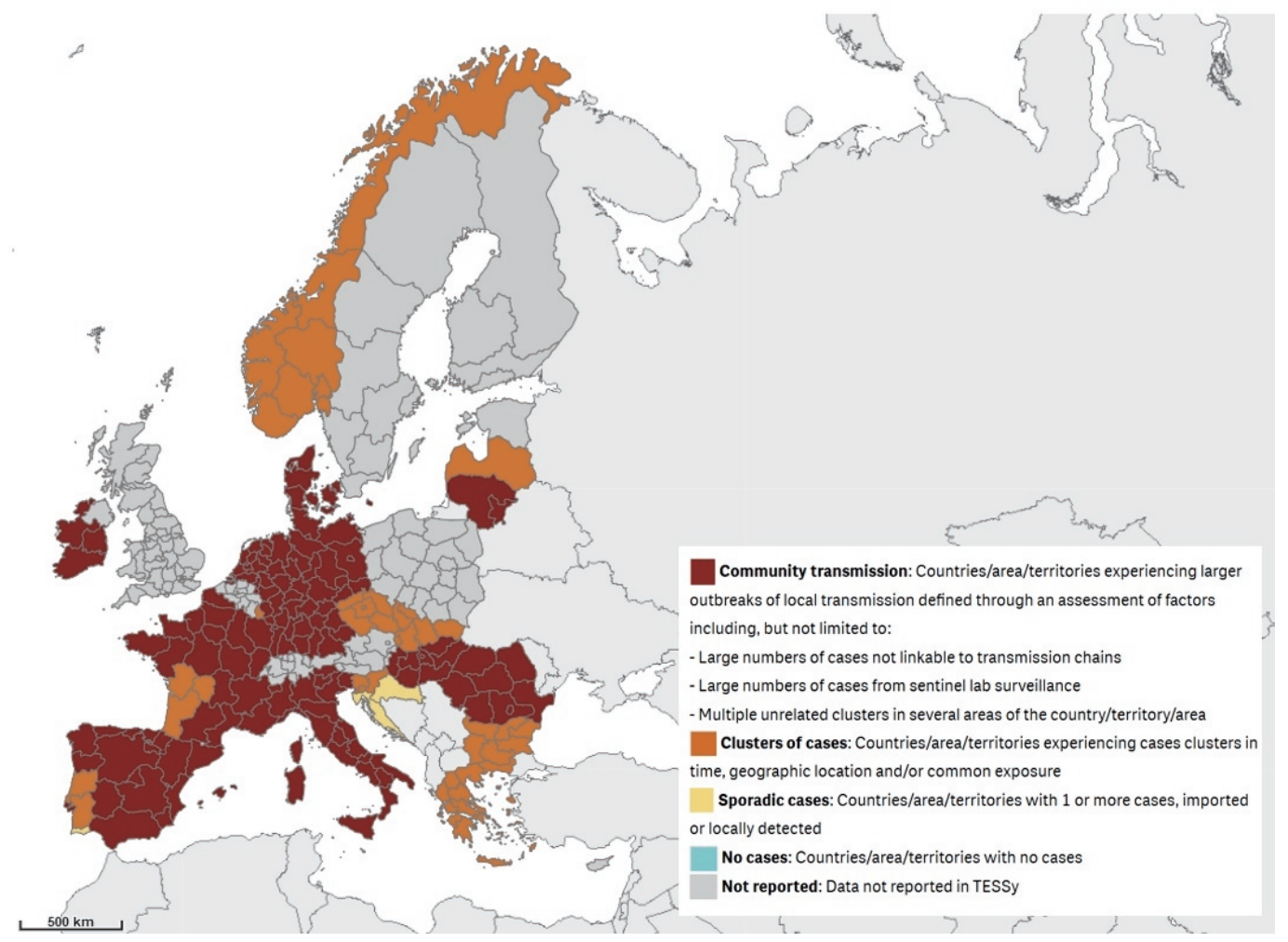

FIGURE 20.1

Country Level Information on COVID-19 in Europe (Source: [13])

and decisions can be taken. The role of EU institutions has evolved over time, but national institutions also continue to play key roles by performing their traditional functions at the national level. This fact became very evident again in the initial phase of the COVID-19 outbreak, when political decisions were predominantly taken by the national member governments. From a certain level, this also applies to the provision of information, including geospatial health information. In the following sections, this will be illustrated using selected EU countries as examples.

\subsubsection{National and Sub-National Level}

Providing up to date information about the distribution of the virus and prevailing measures is key to make informed decisions on the one hand and on the other hand to inform citizens and organisations to comply with the policy within a country (awareness raising or sensitization). Most up-to-date data at sub-national level, either at NUTS 3 level or even more detailed, can be found in national dashboards. Some use cases will be presented here.

\subsubsection{France}

The French government has published a dashboard on the internet that presents COVID-19 related information geographically. It is possible to retrieve the information on a particular date. Hence it is possible to consult the course of the disease geographically. Various information is included: the current level of precautionary measures based on the number of detected cases (Figure 20.2), the transfer of patients within France and Europe, test sampling locations and their status and the test results per administrative unit. 


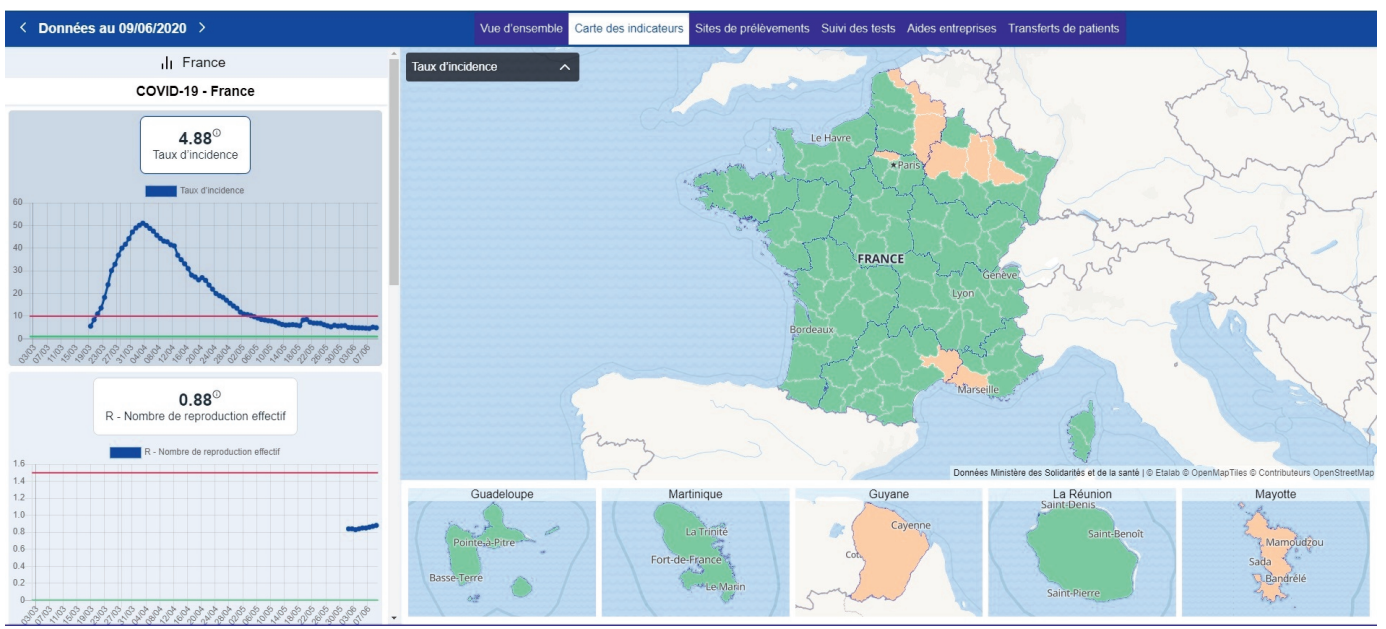

\section{FIGURE 20.2}

Vigilance Map for France on 9 June 2020 (Source: [14])

\subsubsection{The Netherlands}

After the crisis team became operable, the national insitute for public health and the environment (RIVM), operating under the Ministry of Health, Welfare and Sport, became responsible for dissemination of Covid-19 related data and figures. The government in the Netherlands chose to publish most Covid-19 related information in traditional graphs instead of mapping it. Only the relative number of Covid-19 cases and hospitalized people per 100,000 inhabitants per municipality were visualized geographically. Compared to absolute numbers, this relative number allows to compare between municipalities with varying population densities. The media mapped the confirmed hospitalized patients over time at municipality level to show the spreading of the disease of the country over time [15]. Here, one can see that the disease was spread across the country from the south to the west and north due to various events, e.g. spring holiday and carnival, and movements of people between the regions. The three most norther provinces were hardly affected, most likely due to their remote character relative to the location of the big cities in the west and south.

\subsubsection{Germany}

At March 2020, Germany had introduced consistent measures to combat COVID-19 that were implemented nationwide. Over time, it became clear that the spread of infection is mainly concentrated in local hotspots, without it being possible to predict such locations precisely. Therefore, on 6 May 2020 policy makers agreed to respond to regional dynamics of new infections on a local basis, using the NUTS 3 level administrative units as the spatial reference. It was decided that in districts or urban municipalities, the German NUTS 3 level units, with a cumulative rate of more than 50 new cases of infection per 100,000 inhabitants within the previous seven days, restrictions adapted to the local situation will immediately be implemented. A cumulative rate of more than 35 new cases of infection per 100,000 inhabitants within the previous seven days was set as threshold for early warning [16].

Figure 20.3 shows the temporal dynamics of infections over time including the numbers as of 12 June 2020, with one NUTS 3 unit surpassing the intervention threshold of 50 infections per 100,000 inhabitants within the previous seven days (LK Aichach-Friedberg, 59 cases), and five units reaching the early warning limit of 35 infections per 100,000 inhabitants within the previous seven days (LK Cuxhaven 44 cases, SK Bremerhaven 41 cases, LK Sonneburg 41 cases, LK Göttingen 37 cases, LK Coburg 35 cases).

The Robert-Koch-Institute, Germany's public health institute, collects data on, among others, 
12 Dynamics of infections.png

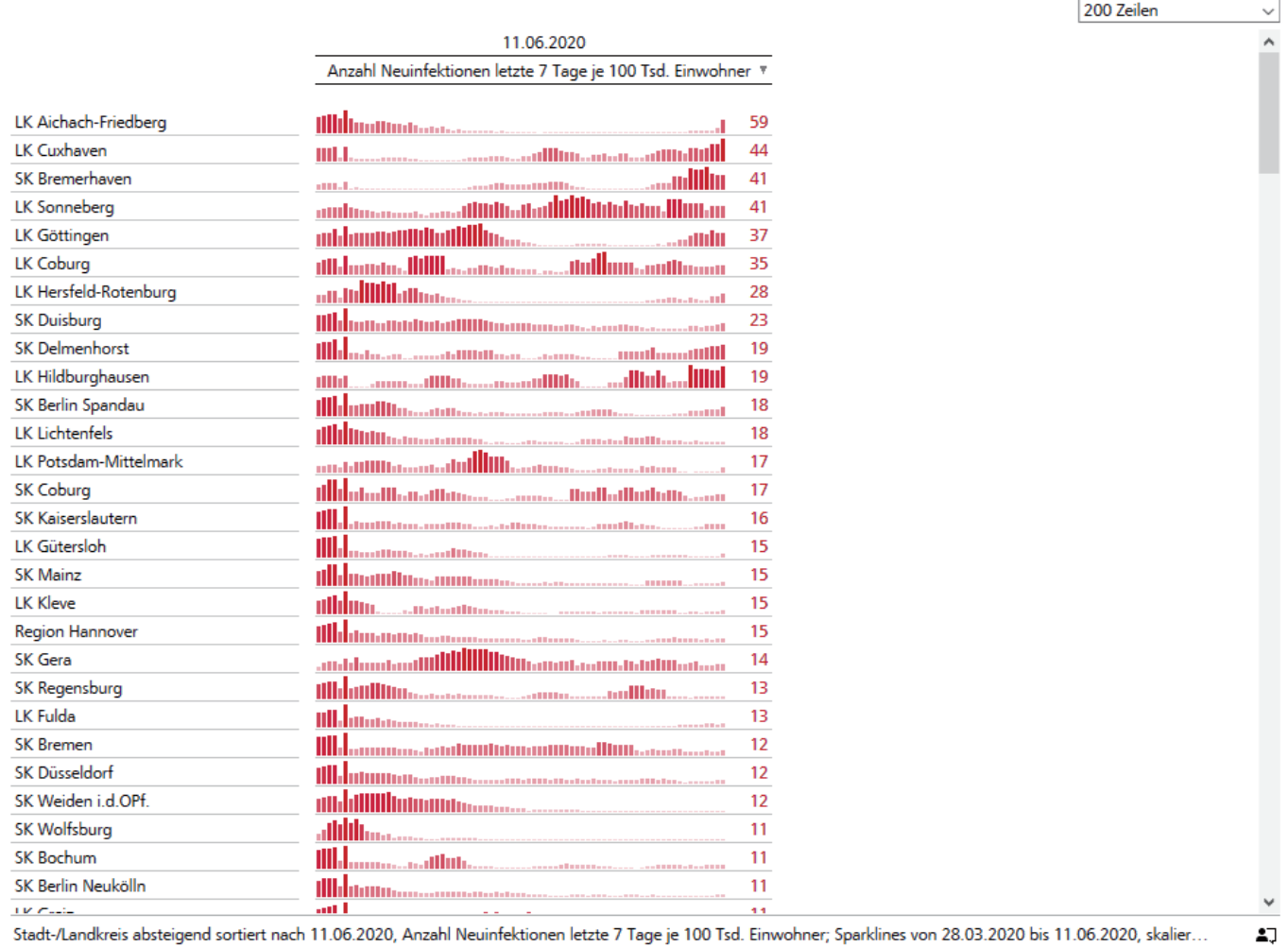

\section{FIGURE 20.3}

Dynamics of Infections per 100,000 Inhabitants in Germany at the Nuts 3 Level (Source: [17])

infectious diseases; it communicates information by a COVID-19 specific dashboard and offers the underlying data to the general public on a daily updated basis. The data can be downloaded in different formats. Retrieving the data via an ESRI ArcGIS Feature Service is a very versatile way to get direct access to the attributes and geometries of the layers. Geospatial data retrieved via a Web Feature Server make it possible to use the complete set of GIS tools for comprehensive spatiotemporal analyses. For example, the period of time and further spread of local outbreaks can be tracked. At the same time, using such spatially aggregated data preserves data protection and data privacy.

A major event illustrating the benefits of locally adapted measures occurred in June 2020, when a COVID-19 outbreak was detected at a German meat processing plant in the week ending 21 June 2020 [18]. The outbreak near Gütersloh (see Figure 20.4, prism in red) was first reported on Wednesday 17 June, when 400 workers tested positive. By Friday 19 June, that number had doubled to 803 and it climbed further to 1,331 by Sunday 21 June. The number of confirmed infections for the corresponding NUTS 3 unit LK Gütersloh rose to 264 per 100,000 inhabitants within one week, thus far exceeding the intervention threshold of 50 infections. Seven days high incidences in neighbouring districts are linked to the outbreak in Gütersloh [19]. The now localised lockdown strategy permitted the local authorities to limit the quarantine order to the 5,500 employees of the plant and their families, rather than imposing a broad lockdown affecting the social and economic lives of many millions of people in the whole country. 


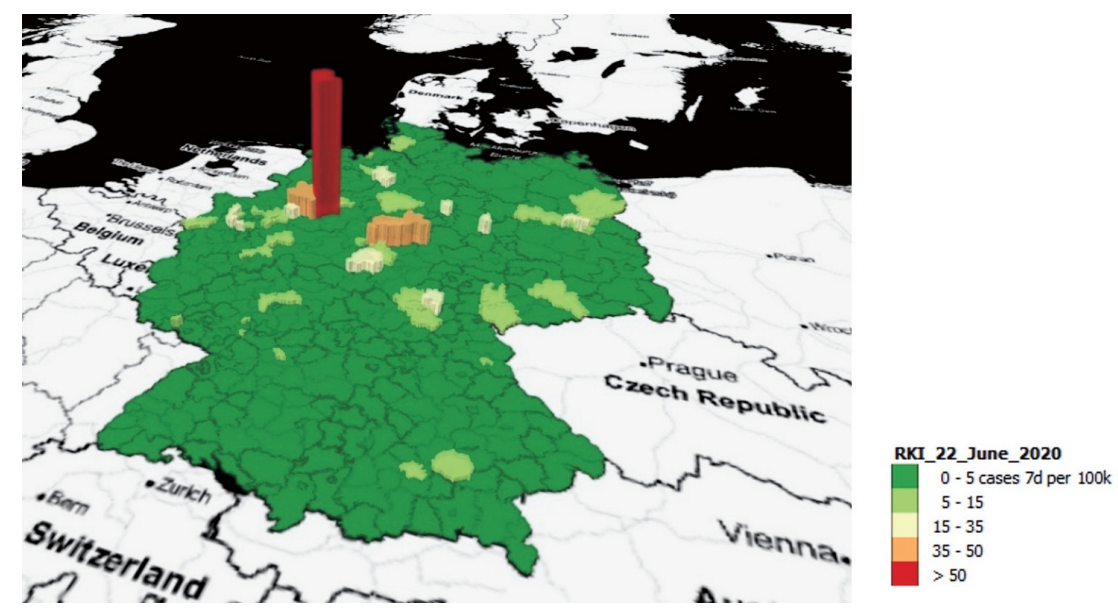

\section{FIGURE 20.4}

Visualization at Nuts 3 Level of a Major Local COVID-19 Outbreak in Germany, June 2020. Source: Own Representation, Data Based on Robert Koch-Institut (Rki), DL-de/by-2-0, Map Tiles by Stamen Design, Under CC by 3.0. Data by Openstreetmap, Under CC by SA

\subsection{Shortcuts and Challenges of COVID-19 Data Provision}

Data problems in providing COVID-19 data are manifold. The Washington Post expresses the facts in this perfect, concise statement: 'Case counts are consistently inconsistent. Reporting practices differ from country to country, state to state, even county to county' [20].

The Johns Hopkins University, Baltimore, Maryland, USA, maintains a coronavirus resource center [21], a globally intensively used resource for better understanding of and information about the virus. The researchers of Johns Hopkins University are doing very valuable work by collecting data and, at the same time, by managing a list of open issues [22]. At the time of writing this article, the list consists of 1,344 open issues, with 899 issues already closed. A comprehensive review of the existing data problems is beyond the scope of this article. For illustration purposes, however, some relevant exemplary problems shall be addressed briefly.

1. The Quest for Reliable Data

The number of confirmed cases depends largely on the number of conducted diagnostic tests: the more laboratory tests are conducted, the more positive cases are discovered. A lack of test material or testing capacity hampered some countries to produce reliable data regarding the number of positive tested persons. As an alternative other data were used to monitor the progress of the disease, such as the number of hospitalized people.

2. The Timeliness of Reporting

There is no obvious reason why both the number of confirmed cases of disease and the number of disease-induced deaths should be lower on weekends than on working days. However, this is exactly what most country statistics display. It seems to be much more likely that a smaller number of cases are registered at weekends because fewer diagnostic tests are conducted at weekends, or because there are delays in reporting due to staff at health offices not being on the job, or for other reasons. The timeliness of the data therefore fluctuates without this being precisely documented in many cases.

3. The Need for Unambiguous Definitions

Differences in the definition of diagnosed and reported cases, even changes in the definition occur. For illustration purposes, some application cases shall be mentioned. 
China reported 15,132 new cases for a single day, February 12 2020. The reason for this spike was a change in how cases are diagnosed and reported in Hubei province starting on the same day. In the Hubei province only, medical professionals can classify a suspected case of COVID-19 as a clinically confirmed case, without having to have a laboratory confirmation. Of the 15,132 new cases reported, only 1,820 were new laboratory confirmed cases, all others were due to the changed counting method of the cases [23].

In a similar way the U.S. moved from counting only laboratory confirmed cases to counting 'confirmed and probable cases and deaths' [24].

In early April, France reported 17,827 additional cases and 532 plus 884 additional deaths from nursing homes, that had not previously been included in the official counts. Similarly, the daily figures for COVID-19 deaths in one country might, for example, only include those dying in hospitals, while other countries include deaths in nursing homes in their figures [23].

\subsection{Discussion}

Due to the epidemic character and unfamiliarity with the disease, no standardized methodology to collect data was available. This makes it difficult to compare between countries and to provide decision-makers and the public with reliable information. For logic reasons, each country drafted their own procedures and policy regarding the testing strategy, and these might have been altered over the course of the epidemic. Many variables influenced the strategy, for example the availability of testing material, the capacity of health care to treat patients, and political viewpoints. Some countries (initially) ignored or underestimated the impact of the infectious disease, which led to a more severe outbreak. The country examples show nicely which data was collected and were regarded 'reliable' enough to be published.

Apart from variations in the type of data collected, also the purpose of geospatial data - i.e. the use case - differed. On the one hand, geospatial information played an important role to inform the public about the severity of the outbreak, the spatial distribution and possible measures that applied in particular local regions or municipalities. Graphics and maps in a complementary dashboard are an important means for communication.

The other role of geospatial information relates to analytical purposes. Governments need reliable information to decide how to respond to the crises. Of course, with a new disease, much is unknown, and politicians have few resources to rely on, except for knowledge and expectations from the experts. However, over the course of the epidemic, it is essential to collect data to monitor progress and effectiveness of imposed measures, such as the closure of facilities and restrictions to travel.

The purpose for which geospatial information is used, should relate to how the geospatial information is presented and which means are used. Can it best be presented in a simple graph or is a map better? And how to include specific spatial developments related to spread of the disease across the country, or across the region? The level of detail provided should be considered and related to the purpose as well. A comparison between countries or between continents requires a different presentation of data, e.g. more accumulation is needed, then a detailed location-specific analysis for decision-makers.

\subsubsection{The Data Problem}

Every presentation and analysis of geospatial information is a result of the underlying data. Responding to a global epidemic requires coordinated action at all levels, both global and supranational, as well as national and local. As discussed in section 'Shortcuts and challenges of COVID-19 data provision', there is a lack of internationally harmonized standards for data collection and data provision of COVID-19 data. This limitation makes it difficult, if not impossible, to compare data collected in different countries and thus hinders information and possibly informed joint political action at the international level. 
Other global issues, such as achieving the Sustainable Development Goals (SDG) 2030, face similar data problems. In July 2017, the United Nations General Assembly adopted a Global Indicator Framework consisting of 232 statistical indicators designed to measure the SDG goals and targets [25]. Populating those indicators poses enormous challenges, which is even described as an 'unprecedented statistical' challenge [26]. MacFeely [27] distinguishes two different groups of SDG indicators: Indicators that are conceptually clear, have an internationally established methodology, and for which standards are available, and indicators, for which internationally established or standards are not yet available, but are being (or will be) developed or tested.

\subsubsection{Public Health Data and Statistical Information}

As discussed above, health data are regularly provided by national health authorities in an aggregated form within the same national framework that is used to manage statistical national data. For this reason, a globally well-defined integrated statistical and geospatial framework could serve as an excellent basis for managing not only relatively low-dynamic statistical data, but also highly-dynamic health data, such as those generated in the event of a global epidemic. In this way spatiality of statistical information [28] and dynamic health data could go hand in hand. INEGI, the National Institute of Statistics, Geography and Informatics of Mexico [29] implemented one of the first geostatistical dashboards presenting COVID-19 data and statistical indicators in an integrated form [30]. The analysis of confirmed, suspected, negative COVID-19 cases and COVID-19 deaths in the context of statistical indicators at both state and municipality level (population density, population aged 60 and over, educational and economic characteristics, health services, hospital infrastructure, etc.) makes it possible to assess the level of vulnerability of the population (see [31]).

\subsubsection{Public Health Data and Spatial Data Infrastructures}

By definition, a pandemic is 'the worldwide spread of a new disease' [2]. Consequently, a pandemic requires a worldwide coordinated response. Due to global dependencies and exchange of goods and people, there is a need to coordinate actions to limit further spreading of the disease. However, each country has its own authority and powers to take decisions. In Europe, countries developed their own strategy to counteract the disease despite a shared understanding of the potential impact of the outbreak on society. A parallel can be drawn with the management of geospatial COVID-19 data. Each country made their own decisions regarding which data to collect, how to measure and monitor progress of the outbreak, and how to display and disseminate the information to the public.

At the beginning of this century, a similar situation existed with regard to the Spatial Data Infrastructures (SDI) of the EU Member States. To overcome the unsatisfactory situation of lack of interoperability between the different National Data Infrastructures (NSDI), it was decided to create a European Spatial Data Infrastructure to enable the sharing of environmental geospatial information among public sector organisations, to facilitate public access to geospatial information across Europe and to support policy-making across national borders. In 2007 the INSPIRE (INfrastructure for SPatial InfoRmation in Europe) Directive came into force, with full implementation required by 2021 [32]. INSPIRE is based on the National Data Infrastructures established and operated by the Member States of the European Union.

Although long-established standards for a European Spatial Data Infrastructure are available, it does not currently seem possible to provide a high-quality European dashboard capable of disseminating COVID-19 data from individual Member States in a standardized form. Part of the reason lies in the novice nature of the disease in combination with the diverse institutional settings in each country. Most of these institutions are not oriented towards geospatial information, but deal with healthcare, public health and public order and safety.

Murgante et al. [33] publish the results of a comprehensive research on the COVID-19 outbreak in Italy, in which health, geographical and planning aspects were equally considered and integrated. The aim of the study was to conduct a fine and disaggregate analysis at the local level. The analysis demonstrated the spatial diffusion and the distribution of the COVID-19 outbreak in Italy by referencing some major groups of variables: land use, air quality, climate and weather, population, health and life expectancy. Many high-resolution data on land use, air quality, climate 
and weather, population, health and wellness were needed as input data for such detailed analyses. The authors report that they had to collect data from many different sources, COVID-19 data from the Italian Ministry of Health, from regional administrations, from local health agencies, even from newspapers. Socio-economic and demographic data came from the Italian Statistical Institute, environmental data and indicators had to be collected from different sources, such as the Higher Institute for Environmental Protection and Research, the World Health Organization, the European Environmental Agency, the Italian Automobile Club. Weather and wind data had to be retrieved from other websites, data on air quality and weather conditions from special dashboards.

Considerable preparatory work was needed to integrate those data so that could be used as input for analyses. Most of this data could be provided within a well-defined spatial data infrastructure, directly and instantly accessible, clearly linked to georeferenced statistical, health and other relevant information.

\subsubsection{Integration of Public Health Data, Statistical Data and Basic Geospatial Data}

To take full advantage of the wealth of information available in the various institutions it is necessary to develop and implement solutions for the integrated management of public health data, general statistical data and basic geospatial data.

Since 2016, the global 'integration of spatial, statistical and other related information' has been explicitly on the agenda of the UN Committee of Experts on Global Spatial Data Management $[34,35]$. The COVID-19 epidemic demonstrates in a perhaps unparalleled way the need to provide globally integrated spatial, statistical and health-related information, adapted to the needs of very diverse users.

\subsection{Conclusions}

A pandemic, a worldwide-spread of a new disease, requires a worldwide coordinated response. An infectious disease spreads over space and time at different speeds and can cause local outbreaks. A new disease calls for new insights, which must be gained through synoptic observations from different perspectives, medical, social and economic. Spatio-temporal analysis can help to gain such new insights by relating disease-related data, such as case numbers, hospital occupations, fatality rates, etc. which evolve over time, to statistical indicators and to the locations to which they refer.

In order for spatio-temporal information systems to develop their full potential, the characteristics of the data they contain must be clearly defined and the underlying spatial reference units must be consistently defined. Such high-quality and trusted information can help decision-makers to intervene at the right time and at the right place, rather than relying on general figures. More than that, a quality controlled spatiotemporal database can support post-pandemic analysis in many different areas of interest.

Much groundwork has already been done in the domain of spatial data infrastructures, both at national and supranational level. At this stage, committees and working groups are concentrating on the development of solutions for the integration of statistical information into such infrastructures, which will then be implemented by the individual countries.

The epidemic demonstrates the urgent need for an integrated spatial and statistical information system at the global level, but also at the country level and beyond. This chapter showed how various countries implemented a system at the national level, which led to a range of diverse solutions, interfaces, and management information. This pluralism in national solutions was integrated at the European level into a data platform based on the input from individual member states and their systems. After some initial hick-ups, the information was used to discuss interventions at the European level and feed these back into national actions, e.g. regarding cross-border travel 
regulations between countries. However, the potential of an integrated system at the country level and the European level is not fully taken advantage of yet due to mentioned barriers. Once the systems at the country level have matured and aligned, it will leverage the benefits for both government and societal resilience at the country level and at European level.

An integrated system providing basic geospatial data, statistical data, and public health data in one and the same framework would make it possible to retrieve georeferenced information in near real time at all levels - global, supranational, national and local - in a timely and user-oriented manner.

It remains to be investigated to what extent and how the organizational, technical, and legal challenges of such an initiative can be mastered.

\section{References}

[1] WHO World Health Organization. Global influenza strategy 2019-2030. License: CC BY-NC-SA 3.0 IGO, 31 p., ISBN 978-924-151532-0. World Health Organization, 2019. URL https://apps.who.int/iris/handle/ $10665 / 311184$.

[2] WHO World Health Organization. Coronavirus Disease (COVID-2019) Situation Reports. World Health Organization, 2020. URL https://www. who.int. Accessed on June 2020.

[3] Mark D Verhagen, David M Brazel, Jennifer Beam Dowd, Ilya Kashnitsky, and Melinda C Mills. Forecasting spatial, socioeconomic and demographic variation in COVID-19 health care demand in England and Wales. BMC Med 18, 203, 2020. URL https://doi.org/10.1186/s12916-020-01646-2.

[4] Duygu Balcan, Vittoria Colizza, Bruno Gonçalves, Hao Hu, José J. Ramasco, and Alessandro Vespignani. Multiscale mobility networks and the spatial spreading of infectious diseases. Proceedings of the National Academy of Sciences of the United States of America, 106(51), 2009. URL https://www.pnas.org/content/ $106 / 51 / 21484$.

[5] J.A Backer, Don Klinkenberg, and Jacco Wallinga. Incubation period of 2019 novel coronavirus (2019-nCoV) infections among travellers from Wuhan, China, 20-28 January 2020. Euro Surveill. URL https://www. eurosurveillance.org/content/10.2807/1560-7917.ES.2020.25.5.2000062\#html_fulltext.

[6] Wentao Yang, Min Deng, Chaokui Li, and Jincai Huang. Spatio-Temporal Patterns of the 2019-nCoV Epidemic at the County Level in Hubei Province, China. International Journal of Environmental Research and Public Health, 17:2563, 2020. doi: 10.3390/ijerph17072563. URL www.mdpi.com/journal/ijerph.

[7] The Health Foundation. Excess mortality rates for the period from 28 February 2020 March to 22 May 2020, nationwide figures. 2020. URL https://www.health.org.uk/news-and-comment/charts-and-infographics/ understanding-excess-deaths-countries-regions-localities. Accessed on June 2020.

[8] The Health Foundation. Excess mortality rates for the period from 28 February 2020 March to 22 May 2020 in hotspots. 2020. URL https://www.health.org.uk/news-and-comment/charts-and-infographics/understandingexcess-deaths-countries-regions-localities. Accessed on June 2020.

[9] OGC. 2020. URL https://www.ogc.org/resources-for-COVID-19-from-ogc. Accessed on October 2020.

[10] Pierre Goovaerts. Geostatistical analysis of health data: State-of-the-art and perspectives. In A. Soares et al. (eds.), geoENV VI - Geostatistics for Environmental Applications, pages 3-22. C Springer Science+Business Media B.V., 2008. doi: 10.1007/978-1-4020-6448-7_1.

[11] UN-GGIM. 2020. URL https://ggim.un.org/IGIF/. Accessed on October 2020.

[12] EUROSTAT. Regions in the European Union, edition 2018, Nomenclature of territorial units for statistics -NUTS 2016/EU-28. Publications Office of the European Union, Luxembourg, 2018. doi: 10.2785/475524.

[13] European Centre for Disease Prevention and Control. Country level information on COVID-19 in Europe. 2020. URL https://qap.ecdc.europa.eu/public/extensions/COVID-19/COVID-19.html. Accessed on 4 June 2020.

[14] French government. Vigilance map for France at 9 June 2020. 2020. URL https://www.gouvernement.fr/infocoronavirus/carte-et-donnees\#activite-epidemique. Accessed on 8 September 2020.

[15] RTL nieuws. 2020. URL https://www.rtlnieuws.nl/nieuws/nederland/artikel/5128431/corona-gemeentenederland-verspreiding-wanneer-haard-besmettingen. Accessed on June 2020.

[16] German Federal Government. Press release number151/20 of 6May2020. 2020. URL https: //www.bundesregierung.de/resource/blob/973812/1751456/c197062365f7e60780e9039dc4e336ee/2020-05-06beschluss-bund-laender-eng-data.pdf?download=1. Accessed on June 2020. 
[17] Bissantz Business Intelligence. Dynamics of infections per 100,000 inhabitants in Germany at the NUTS 3 level. 2020. URL https://data. bissantz.de/Session. aspx?application=2000\#s-237. Accessed on 13 June 2020.

[18] World News. German coronavirus outbreak at abattoir infects more than 1,000. 2020. URL https://www.reuters.com/article/us-health-coronavirus-meat-toennies/german-coronavirus-outbreakat-abattoir-infects-more-than-1000-idUSKBN23R0Q5.

[19] Robert Koch Institute. Coronavirus Disease 2019 (COVID-19) Daily Situation Report of the Robert Koch Institute22/06/2020 - UPDATED STATUS FOR GERMANY. 2020. URL https://www.rki.de/DE/Content/ InfAZ/N/Neuartiges_Coronavirus/Situationsberichte/2020-06-22-en.pdf. Accessed on June 2020.

[20] The Washington Post. Millions track the pandemic on Johns Hopkins's dashboard. Those who built it say some miss the real story, by Kyle Swenson, June 29, 2020 at 9:50 p.m. GMT+2. 2020. URL https://www. washingtonpost.com/local/johns-hopkins-tracker/2020/06/29/daea7eea-a03f-11ea9590-1858a893bd59_story.html. Accessed on June 2020.

[21] Johns Hopkins University. 2020. URL https://coronavirus.jhu.edu/. Accessed on October 2020.

[22] GitHub. 2020. URL https://github.com/CSSEGISandData/COVID-19/issues. Accessed on June 2020.

[23] Worldometer. COVID-19 coronavirus pandemic. 2020. URL https://www.worldometers.info/coronavirus/.

[24] CDC. Centers for Disease Control and Prevention. 2020. URL https://www.cdc.gov/coronavirus/2019ncov/cases-updates/cases-in-us.html. Accessed on June 2020

[25] UN (United Nations) General Assembly. Resolution adopted by the General Assembly on 6 July 2017 - Work of the Statistical Commission pertaining to the 2030 Agenda for Sustainable Development. Seventy-first session. A/RES/71/313. 2017. URL https://undocs.org/A/RES/71/313. Accessed on June 2020.

[26] Lebada A.M. Member states, statisticians address SDG monitoring requirements. 2016. URL http://sdg. iisd.org/news/member-states-statisticians-address-sdg-monitoring-requirements/. Accessed on June 2020.

[27] Steve MacFeely. Measuring the Sustainable Development Goal Indicators: An Unprecedented Statistical Challenge. Journal of Official Statistics, 36(2):361-378, 2020. doi: 10.2478/jos-2020-0019.

[28] UN (United Nations). Economic Commission for Europe, Conference of European Statisticans, In-depth review of developing geospatial information services based on official statistics. Meeting of the 2015/2016 Bureau, Luxembourg. 2016. URL https://www.unece.org/fileadmin/DAM/stats/documents/ece/ces/bur/2016/ February/02-In-depth_review_on_developing_geospatial_information_final.pdf. Accessed on June 2020.

[29] INEGI. 2020. URL https://en.www.inegi.org.mx. Accessed on October 2020.

[30] INEGI. 2020. URL https://gaia.inegi.org.mx/covid19/. Accessed on October 2020.

[31] INEGI. Covid-19: Context indicators GeoStatistical-dashboard. 2020. URL https://www.cepal.org/ sites/default/files/presentations/covid-19-strategies-geospatial-response-lac-mexico_0.pdf. Accessed on October 2020.

[32] European Union (EU). Directive 2007/2/EC of the European Parliament and of the Council of 14 March 2007 establishing an Infrastructure for Spatial Information in the European Community (INSPIRE). OJ L 108, 25.4.2007, p. 1-14 (BG, ES, CS, DA, DE, ET, EL, EN, FR, IT, LV, LT, HU, MT, NL, PL, PT, RO, SK, SL, FI, SV) Special edition in Croatian: Chapter 13 Volume 030 P. $270-283.2007$. URL https://inspire. ec. europa.eu/documents/directive-20072ec-european-parliament-and-council-14-march-2007-establishing.

[33] B Murgante, G Borruso, G Balletto, P Castiglia, and M Dettori. Why Italy First? Health, Geographical and Planning Aspects of the COVID-19 Outbreak. Sustainability, 12, 2020, 5064.

[34] UN-GGIM. UN Committee of Experts on Global Spatial Data Management, Sixth session New York. 2016. URL http://ggim.un.org/knowledgebase/Attachment1651. aspx?AttachmentType=1. Accessed on June 2020.

[35] European Union/United Nations. The integration of statistical and geospatial information - a call for political action in Europe, UN-GGIM: Europe, Work Group on Data Integration, subgroup 1. Luxembourg: Publications Office of the European Union, Luxembourg, 2019, ISBN 978-92-76-05474-0. 2019. URL https://ec.europa.eu/eurostat/documents/4031688/10158240/KS-03-19-423-EN-N.pdf/c8f75ee12181-288c-1efa-1622c5abb980. Accessed on June 2020. 